\title{
FARKLI EĞİLME DONATISINA SAHİP ULTRA YÜKSEK PERFORMANSLI LİFLİ BETONARME KIRIŞLERDE ÇARPMA ETKİSI
}

\author{
${ }^{1}$ Gamze DEMİRTAŞ ${ }^{(D)}$, ${ }^{2}$ Naci ÇAĞLAR ${ }^{(D)},{ }^{3}$ Yusuf SÜMER \\ 1,2 Sakarya Üniversitesi, Mühendislik Fakültesi, İnşaat Mühendisliği Bölümü, Sakarya, TÜRKIYYE \\ ${ }^{3}$ Sakarya Uygulamah Bilimler Üniversitesi, Teknoloji Fakültesi, İnşaat Mühendisliği Bölümü, Sakarya, TÜRKIYYE \\ ${ }^{1}$ demirtas@sakarya.edu.tr, ${ }^{2}$ caglar@sakarya.edu.tr, ${ }^{3}$ ysumer@subu.edu.tr
}

(Geliş/Received: 31.09.2020; Kabul/Accepted in Revised Form: 14.12.2020)

ÖZ: Ultra Yüksek Performanslı Lifli Beton (UYPLB) karakteristik basınç dayanımı 150-250 MPa ve çekme dayanımı 10-15 MPa civarlarında olan çelik, sentetik, vb. lifler ile güçlendirilmiş kompozit bir yapı malzemesidir. UYPLB birçok yapı elemanında, geleneksel betonlara göre çeşitli avantajlar sağlama potansiyeline sahiptir. Bu çalışmada, UYPLB ile üretilen betonarme kirişlerin çarpma yükleri etkisi altındaki davranışları nümerik olarak incelenmiştir. Çalışmanın ilk aşamasında çarpma yükü altında UYPLB ile üretilen betonarme kirişlerin nümerik olarak analizine imkân sağlayan bir sonlu eleman modeli geliştirilmiştir. Geliştirilen sonlu eleman modelinin doğrulanması literatürden seçilen deneysel çalışma sonuçları ile yapılmış ve modelin UYPLB ile üretilen betonarme kirişlerin çarpma yükleri etkisi altındaki davranışını başarıyla simüle edebildiği gösterilmiştir. Çalışmanın ikinci aşamasında ise doğrulanmış sonlu eleman modeli kullanılarak parametrik bir çalışma gerçekleştirilmiş ve elde edilen sonuçlar çarpma hızı ve donatı oranının UYPLB ile üretilen betonarme kirişlerin davranışı üzerinde önemli bir etkisi olduğunu göstermiştir.

Anahtar Kelimeler: Ultra yüksek performansh lifli betonarme kiriş, Doğrusal olmayan analiz, Çarpma yükü, ABAQUS

\section{Impact Effect on Ultra High Performance Fiber Reinforced Beams with Different Flexural Reinforcement}

\begin{abstract}
Ultra-high performance fiber reinforced concrete (UHPFRC) is a composite structural material with fibers such as steel, synthetic, with a characteristic compressive strength 150-250 MPa and tensile strength around 10-15 MPa. UHPFRC has the potential to provide various advantages over conventional concrete in many structural elements. In this study, the response of reinforced concrete beams produced with UHPFRC subjected to impact load was analyzed numerically. In the first stage of the study, a nonlinear finite element model was developed to simulate the behavior of UHPFRC reinforced concrete beams under impact load. The verification of the developed finite element model was made with the experimental results selected from the literature and it was shown that the model is highly successful to capture the behavior of UHPFRC reinforced concrete beams under impact loads. In the second phase of the study, a parametric study performed by using the validated finite element model and the results exposed that the impact velocity and the reinforcement ratio have an important effect on the response of UHPFRC beams.
\end{abstract}

Key Words: Ultra-high performance fiber reinforced concrete beam, Nonlinear analysis, Impact load, ABAQUS 


\section{GİRİŞ (INTRODUCTION)}

Günümüzde yüksek binalara ve büyük açıklıklı yapı türlerine olan gereksinimlerin artması, yüksek dayanımlı betonlara olan talebi de arttırmaktadır. Bu betonlara çelik, sentetik, vb. lifler katılarak basınç, çekme ve eğilme davranışları oldukça sünek bir hale getirilmektedir. Yeni bir kompozit yapı malzemesi olarak ortaya çıkan Ultra Yüksek Performanslı Lifli Beton (UYPLB); çelik, sentetik, vb. lifler ile güçlendirilmiş, yüksek süneklik, yorulma direnci ve kırılma tokluğuna sahip, karakteristik basınç dayanımı 150-250 MPa ve çekme dayanımı 10-15 MPa civarlarında olan kompozit bir malzemedir (Fujikake ve diğ., 2006; Wille ve diğ., 2011; AFGC, 2013; Demirtaş ve diğ., 2018). Bu üstün özellikler düşük su/çimento oranı (yaklaşık \%2), dane yoğunluğunu maksimize eden ve homojenlik sağlayan çok ince katkı malzemeleri, buhar kürü ve mikro çelik liflerin katkısı ile sağlanmaktadır (Yoo ve Banthia, 2017). UYPLB' nin bu özellikleri sayesinde ani ya da tekrarlı yüklemelere karşı oldukça yüksek dayanıma sahip olması dolayısıyla, nükleer enerji santralleri, askeri yapılar, ulaşım altyapısı, kıyı yapıları gibi dinamik yüklemelere maruz kalabilecek betonarme yapılar için uygun bir malzeme olabilmektedir (Fujikake ve diğ., 2006; Demirtaş, 2019). Fakat UYPLB ile üretilen betonarme elemanların dinamik davranışının incelenmesi ile ilgili literatürde sınırlı sayıda çalışma bulunmaktadır.

UYPLB ile üretilen kirişin dinamik davranışını deneysel olarak inceleyen Fujikake ve diğ. (2006) çalışmalarında, etriye donatısı olmayan kirişte eğilme kırılması gerçekleştiğini raporlamıştır. Othman ve Marzouk (2016); beton tipi, lif içeriği ve donatı oranının UYPLB ile üretilen döşemelerin dinamik davranışına etkilerini deneysel olarak incelemiştir. Lif içeriğinin ve donatı oranının artması ile aynı dinamik yük altında daha az kalıcı deplasman oluştuğunu gözlemlemişlerdir. Yoo ve diğg. (2015), dinamik yükleme altındaki UYPLB ile üretilen kirişlerin eğilme davranışında donatı oranının etkisini incelemiştir. Donatı oranı arttıkça daha az kalıcı deplasman oluştuğunu ve maksimum çatlak genişliğinin azaldığını tespit etmişlerdir. Yoo ve diğ. (2017), dinamik yükleme altındaki UYPLB ile üretilen kirişlerde hacimce $\% 2$ oranında çelik lif kullanılması durumunda hasar seviyesinin azaldığı ve dolayısıyla kalıcı ve maksimum deplasman değerlerinde ciddi oranlara düşmeler oluştuğunu rapor etmişlerdir.

UYPLB, birçok yapı elemanında, özellikle kirişlerde geleneksel betonlara göre çeşitli avantajlar sağlama potansiyeline sahiptir. Bu tür yapı elemanlarının tasarım prosedürünün çok iyi bilinmemesi ve deneysel çalışma için kullanılacak test ekipmanı ve malzemenin yüksek maliyetli olması gibi nedenlerden dolayı UYPLB ile üretilen yapı elemanlarının darbe yükleri altındaki davranışlarının incelendiği çalışmaların literatürde sınırlı sayıda olduğu görülmektedir. Bununla birlikte, hızla gelişen bilgisayar teknolojileri bu tür deneylerin bilgisayar ortamında yapılabilmesine, oluşturulan deney matrislerinin 2 veya 3 boyutlu modellerle hızlı bir şekilde değerlendirilmesine imkân sağlamaktadır (Demirtaş, 2019; Demirtaş ve diğ., 2018; Chen ve Graybeal, 2012; Sümer, 2010; Birtel ve Mark, 2006). Ancak oluşturulan sayısal modellerin eleman davranışını gerçekçi bir şekilde yansıtabildiği mutlaka kanıtlanmalıdır.

$\mathrm{Bu}$ çalışmanın amacı, UYPLB ile üretilen betonarme kirişlerin çarpma yükleri etkisi altındaki davranışlarını incelemektir. Bu amaçla, literatürden seçilen deneysel çalışmadaki betonarme kirişlerin üç boyutlu sonlu eleman modeli oluşturulmuş, nümerik modelin oluşturulması için gerekli modelleme parametreleri açıklanmış ve kirişlerin çarpma yükü etkisi altındaki doğrusal olmayan analizleri yapılmıştır. Doğrusal olmayan analizlerin gerçekleştirilmesinde ABAQUS (Abaqus, 2018) sonlu eleman yazılımı kullanılmıştır. Geliştirilen sonlu eleman modelinin doğrulanması deneysel çalışma sonuçları ile yapılmış ve modelin UYPLB ile üretilen betonarme kirişlerin çarpma yükleri etkisi altındaki davranışını başarıyla simüle edebildiği gösterilmiştir. Doğrulanmış sonlu eleman modeli kullanılarak parametrik bir çalışma gerçekleştirilmiş ve elde edilen sonuçlar grafikler ve çizelgeler halinde sunularak değerlendirilmiştir.

\section{DENEYSEL ÇALIŞMA VERILLERI (EXPERIMENTAL STUDY DATA)}

Geliştirilen sonlu eleman modelinin doğrulanması için literatürden seçilen deneysel çalışma (Yoo ve diğ., 2015) kullanılmıştır. Deneysel çalışmada UYPLB ile üretilen betonarme kirişlerde donatı oranının, eğilme davranışı üzerindeki etkisini incelemek amacıyla 4 farklı donatı oranına sahip kiriş üzerinde 
çarpma deneyleri gerçekleştirilmiştir. Deney numuneleri $2900 \mathrm{~mm}$ uzunluğunda, 200x270 mm dikdörtgen enkesit boyutlarına sahiptir (Şekil 1). Kullanılan boyuna donatı (D13) $12.7 \mathrm{~mm}$ çapında olup, numunelerde donatı oranı sırasıyla \%0.00, \% 0.53, \%1.06 ve \%1.71 olarak tasarlanmıştır (Şekil 1). Deneyler tüm numunelere $1.60 \mathrm{~m}$ yükseklikten $270 \mathrm{~kg}$ ağırlığında kütlelerin serbest düşürülmesi ile gerçekleştirilmiştir (Şekil 2).

Çizelge 1. Yükleme hızı dikkate alınarak elde edilen malzeme dayanımları (Yoo ve diğg., 2015) Table 1. Material strengths obtained considering the strain rate (Yoo et al., 2015)

\begin{tabular}{lccc}
\hline İsim & $\begin{array}{c}\text { Beton Basınç } \\
\text { Dayanımı (MPa) }\end{array}$ & $\begin{array}{c}\text { Beton Çekme } \\
\text { Dayanımı (MPa) }\end{array}$ & $\begin{array}{c}\text { Donatı Akma } \\
\text { Dayanımı (MPa) }\end{array}$ \\
\hline UH-N & 198.9 & 17.6 & - \\
\hline UH-0.53\% & 197.8 & 17.7 & 630.2 \\
\hline UH-1.06\% & 201.3 & 17.8 & 635.2 \\
\hline UH-1.71\% & 199.1 & 16.3 & 629.4 \\
\hline
\end{tabular}

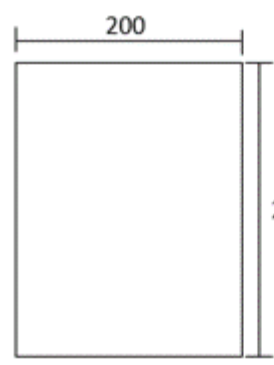

a)

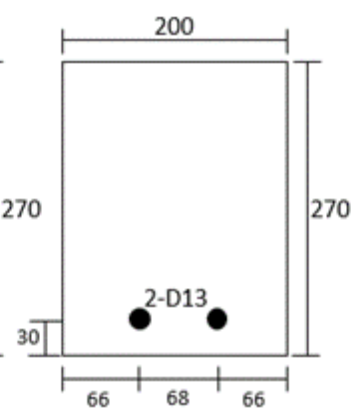

b)

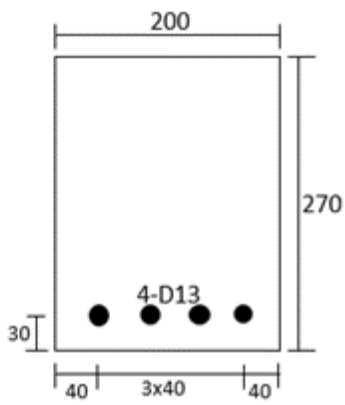

c)

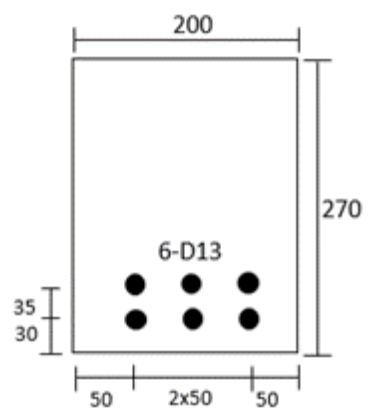

d)

Şekil 1.

Şekil 1. Kesit detay1 a) UH-N b) UH-0.53\% c) UH-1.06\% d) UH-1.71\% (Yoo ve diğ., 2015) Figure 1. Section detail a) UH-N b) UH-0.53\% c) UH-1.06\% d) UH-1.71\% (Yoo et al., 2015)

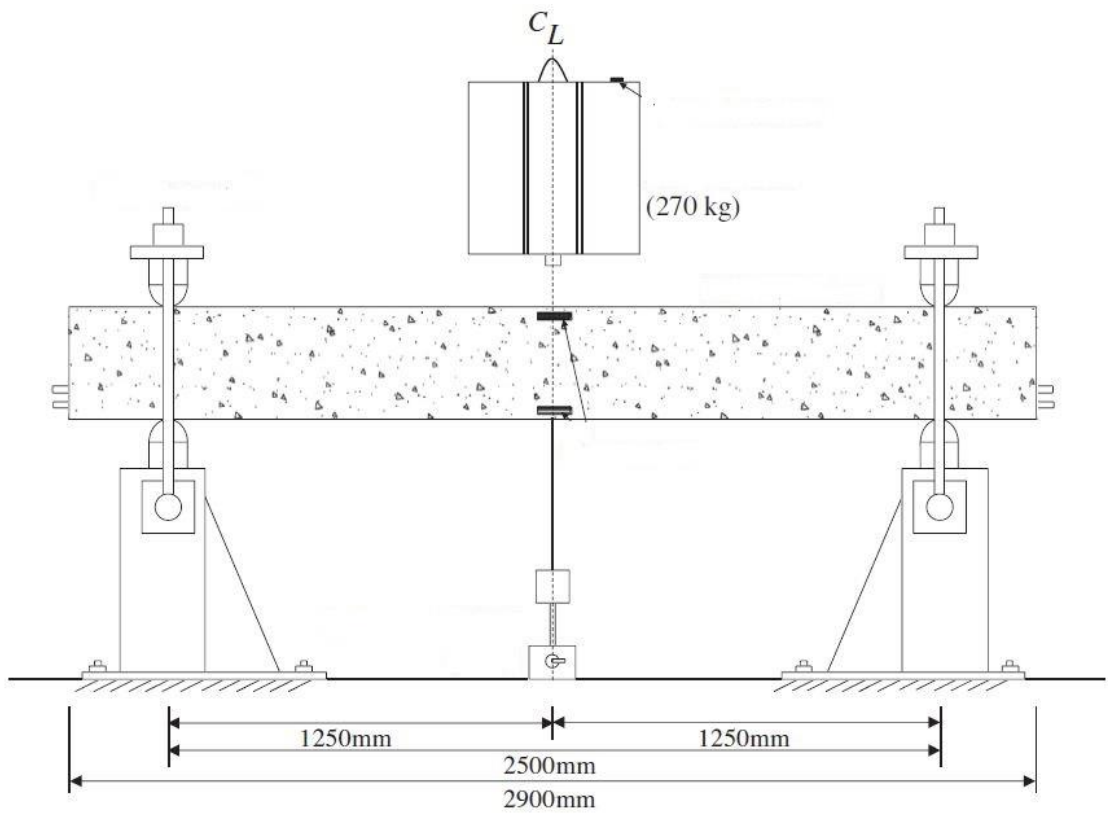

Şekil 2. Çarpma deney düzeneği (Yoo ve diğ., 2015)

Figure 2. Impact test setup (Yoo et al., 2015) 
Deney numunelerinde kullanılan beton malzemesinin statik yükleme etkisi altındaki basınç dayanımı (fc) $152.5 \mathrm{MPa}$, elastisite modülü (E) $44 \mathrm{GPa}$ olarak verilmiştir. Dinamik yükleme etkisi altında, yükleme hızına bağlı olarak beton dayanımının arttığı bilinmektedir. Dinamik yüklemelerde oluşan şekil değiştirme hızı (strain rate) etkisi dikkate alınarak hesaplanan beton ve donatı mekanik özellikleri Çizelge 1 'de verilmiş ve modelleme için çizelgedeki değerler kullanılmıştır.

\section{SONLU ELEMAN MODELI VE PARAMETRELER (FINITE ELEMENT MODEL AND PARAMETERS)}

Darbe etkisi altındaki deneysel analizleri yapılan numunelerin nümerik analizleri ABAQUS sonlu eleman programı kullanılarak yapılmıştır. Doğrusal olmayan dinamik analizler için ABAQUS programında açık (explicit) ya da kapalı (implicit) direk integrasyon yöntemleri kullanılabilmektedir. Açı dinamik analiz yöntemi, çarpma etkisi gibi kısa süreli problemlerin çözümünde daha hızlı ve daha verimli sonuçlar verdiği için bu çalışma kapsamında kullanılmıştır (Abaqus, 2018).

Deney sonuçlarının elde edilmesinde sonlu eleman sınır koşullarının doğru tanımlanması büyük önem taşımaktadır. Bu doğrultuda mesnetler deneyde verilen konumlarda ilgili düğüm noktalarına tanımlanmıştır. Deney verilerine göre bu düğüm noktalarının $X$ yünündeki hareketleri ve $Z$ yünündeki dönmeleri serbest bırakılmıştır. Çelik çarpma ağırlığı rijit cisim (rigid body) özelliği kullanılarak modellenmiş ve cismin orta noktasında belirlenen referans noktasına kütlesi ile tanımlanmıştır. Çarpma kütlesinin hareketi, sadece kirişin düzlemine dik doğrultuda hareket edebilecek şekilde sınırlandırılmıştır. Deneysel verilerden elde edilen çarpma anındaki hız $(5.60 \mathrm{~m} / \mathrm{s})$ kütleye atanmış ve analiz öncesi kütle kiriş yüzeyine çok yakın bir şekilde konumlandırılmışır. Çarpma ağırlığı ve kiriş arasındaki çarpma teması "general contact interaction" özelliği kullanılarak tanımlanmıştır. Kontak etkileşimi için "hard contact" özelliği ile yüzeylerin birbiri ile tam etkileşimi sağlanmıştır (Şekil 3).

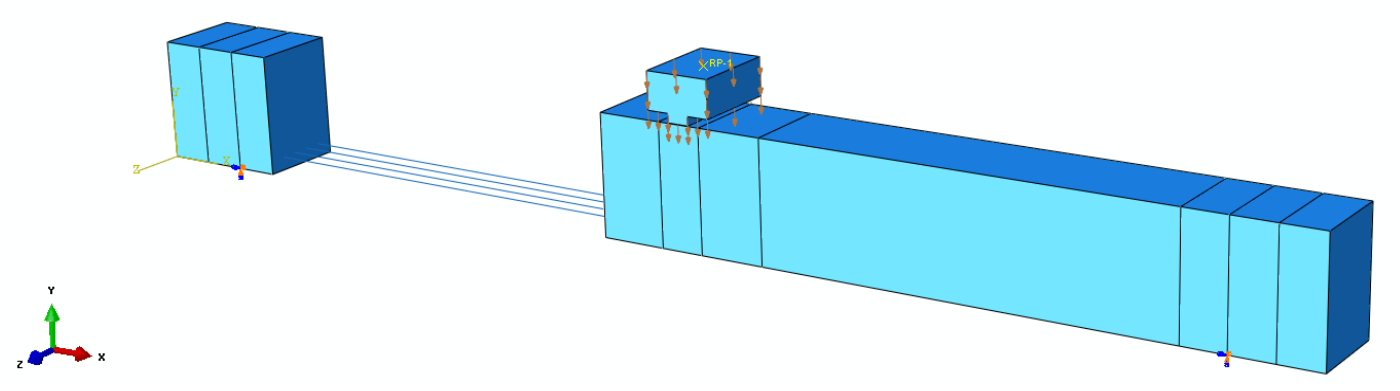

Şekil 3. Sonlu eleman modeli (UH-1.06\%)

Figure 3. Finite element model (UH-1.06\%)

Beton kesitlerin modellenmesinde ABAQUS sonlu eleman kütüphanesinde bulunan 3 boyutlu, 8düğüm noktalı ve azaltılmış integrasyon özelliğine sahip C3D8R elemanı seçilmiştir. Donatı çubuklarının modellenmesinde ise 3 boyutlu analizler için uygun olan eksenel doğrultuda tek serbestlik dereceli, 2düğüm noktalı, lineer doğrusal T3D2 sonlu elemanı kullanılmıştır. Donatı ve beton elemanlar arasında etkileşim kesitler arasında ortak serbestlik derecesi ile hareketi sağlayan gömülü (embedded) özelliği ile tanımlanmıştır.

Donatının doğrusal olmayan davranışını modellemek için gerekli parametreler literatürden seçilen deneysel çalışmadan elde edilmiş olup, bu değerler kullanılarak donatı malzeme modeli oluşturulmuştur. Numunelerdeki donatı mekanik değerleri birbirlerine çok yakın olduğu için, sadece UH-1.06\% numunesi için oluşturulan donatı modeli Şekil 4'de verilmiştir (Çizelge 1). Betonun doğrusal olmayan davranışını tanımlamak için ABAQUS sonlu eleman programında var olan ve plastisite kuramlarına dayanan Beton Hasar Plastisite (BHP) modeli kullanılmıştır. BHP modeli öncelikli olarak, çevrimsel veya dinamik yükleme altında beton yapıların analizi için kullanılmaktadır [9]. Ultra yüksek dayanımlı beton malzeme modelini tanımlamak için gerekli iki temel yenilme mekanizması; basınç kırılması ve çekme çatlamasıdır. (Şekil 3). Şekil 3'ten de görüldüğü gibi BHP modelinin tek eksenli çekme altındaki davranışı maksimum 
çekme gerilmesi değerine ulaşana kadar lineer elastik gerilme şekil değiştirme ilişkisi ile tanımlanır. Bu gerilme değerine ulaşan betonda çekme çatlağı oluşur. Çatlakların ilerlemesi ile dayanım azalmaya başladığı kısım çekme rijitliği olarak tanımlanır (Şekil 5a). Çekme gerilmesindeki bu azalma, gerilme şekil değiştirme ilişkisi ile veya kırılma(çatlama) enerjisi ile tanımlanabilmektedir (Earij ve diğ., 2017).

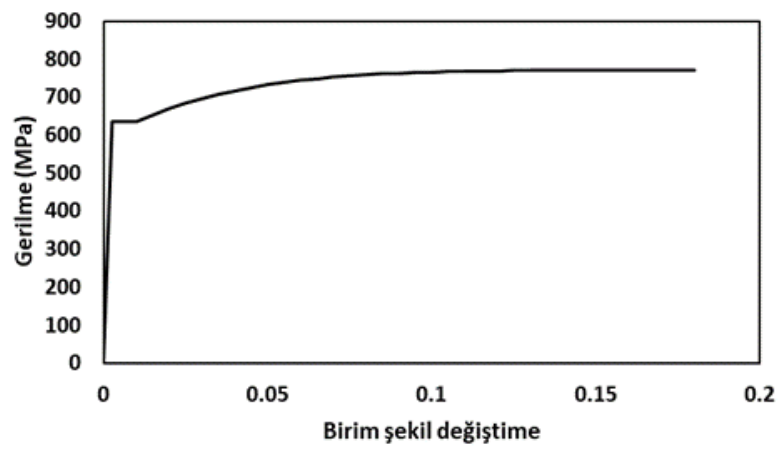

Şekil 4. Donatı mekanik davranışı (UH-1.06\%)

Figure 4. Rebar mechanical behavior (UH-1.06\%)
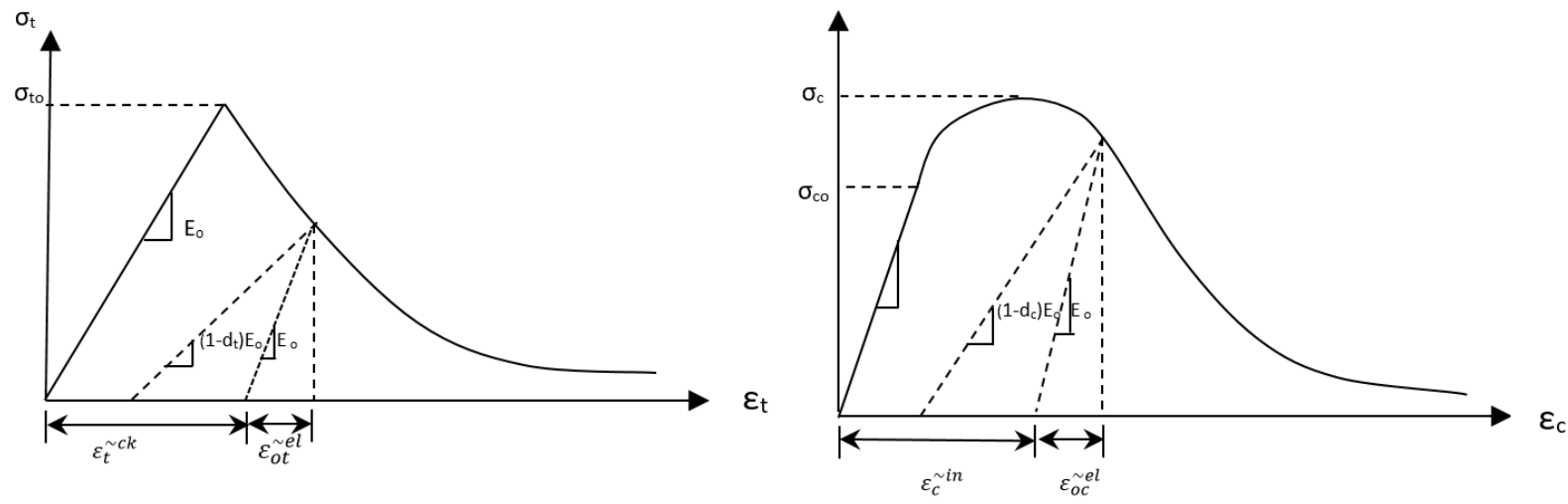

Şekil 5. Eksenel çekme (a) ve basınç (b) altında betonun davranışı (ABAQUS Kullanıcı Dökümanı) Figure 5. Concrete behavior under axial tension (a) and pressure (b) (ABAQUS Analysis User's Manual)

Tek eksenli basınç yüklemesi altında, BHP modeli $\sigma_{c 0}$ değerine kadar lineer bir davranış sergilemektedir. Bu dayanım aşıldıktan sonra betonda plastik şekil değiştirmeler başlamaktadır. $\sigma_{c 0}$ ile $\sigma_{c u}$ arasındaki davranış dayanım pekleşmesi, $\sigma_{\mathrm{cu}}$ aşıldıktan sonra oluşan davranış ise dayanım yumuşaması olarak ifade edilmektedir.

$\mathrm{d}_{\mathrm{c}}$ ve $\mathrm{d}_{\mathrm{t}}$ sırası ile betonun basınç ve çekme etkisi altındaki elastik rijitlikteki azalmayı ifade eden hasar parametreleri olup denklem 1 ve 2 ile ifade edilmektedir (Birtel ve Mark, 2006). Hasar parametreleri 0 ile 1 arasında değişen değerler almaktadır. 0 hasarsız durumu, 1 tam hasarlı durumu ifade etmektedir.

$$
\begin{aligned}
& d_{c}=1-\frac{\sigma_{c} / E_{0}}{\sigma_{c} / E_{0}+\varepsilon_{c}^{\varepsilon^{n}}\left(1-b_{c}\right)} \\
& d_{t}=1-\frac{\sigma_{t 0} / E_{0}}{\sigma_{t 0} / E_{0}+\varepsilon_{c}^{c k}\left(1-b_{t}\right)}
\end{aligned}
$$

Bu modelde güç tükenme zarfını belirlemek için 4 temel parametre gereklidir. Bu değerlerden Eksantriste parametresi $(\epsilon)$, varsayılan değer olarak 0.1 kabul edilmiştir. İki eksenli başlangıç basınç akma gerilmesinin tek eksenli başlangıç basınç gerilmesine oranı $\left(\sigma_{\mathrm{b}} / \sigma_{\mathrm{co}}\right)$ için tipik değerler 1.10 ile 1.16 arasında 
değişmektedir (Lubliner ve diğ., 1989). UYPLB için bu değer 1.05 olarak tavsiye edilmiştir (Curbach ve Speck, 2008). Kc değeri nümerik analizlerde varsayılan değer olarak verilen 2/3 kabul edilmiştir. Dilasyon açısı $(\psi)$ ise, hassasiyet analizi yapılarak belirlenmiştir.

Betonun basınç altında gerilme-şekil değiştirme davranışı deney sonuçlarına dayanarak normal ve yüksek dayanımlı betonlar için ampirik denklemlerle tanımlanmıştır ( $\mathrm{Lu}$ ve Zhao, 2010). Bu çalışma kapsamında UYPLB'nin basınç davranışının modellenmesinde kullanılan malzeme modeli ilk olarak Lu ve Zhao tarafından önerilmiş daha sonra Singh ve diğ. (2017) tarafından ampirik denklemi tekrar düzenlenerek UYPLB'nin gerilme-şekil değiştirme davranışını tek eksenli basınç altında tanımlamıştır. Singh tarafından önerilen formül tam ölçekli kirişin sonlu eleman analizi yönteminde kullanılmış ve dinamik analiz için geçerliliği araştırılmıştır. Basınç davranışı için gerekli formüller denklem 3-8 ile tanımlanmıştır.

$$
\begin{aligned}
& \sigma_{\mathrm{c}}=\mathrm{f}_{\mathrm{c}}^{\prime}\left[\frac{\left(\mathrm{E}_{0} / \mathrm{E}_{\mathrm{sc}}\right)\left(\varepsilon / \varepsilon_{0}\right)-\left(\varepsilon / \varepsilon_{0}\right)^{2}}{1+\left(\mathrm{E}_{0} / \mathrm{E}_{\mathrm{sc}}-2\right)\left(\varepsilon / \varepsilon_{0}\right)}\right] \\
& \sigma_{\mathrm{c}}=\frac{\left(0 \leq \varepsilon \leq \varepsilon_{0}\right)}{1+1 / 4\left[\left[\left(\varepsilon / \varepsilon_{0}\right)-1\right\} /\left\{\left(\varepsilon_{\mathrm{L}} / \varepsilon_{0}\right)-1\right\}\right]^{1.5}} \quad\left(\varepsilon_{0} \leq \varepsilon\right) \\
& \varepsilon_{\mathrm{L}}=\varepsilon_{0}\left[\left(\frac{1.25}{10} \frac{\mathrm{E}_{0}}{\mathrm{E}_{\mathrm{sc}}}+\frac{4}{5}\right)+\sqrt{\left(\frac{1.25}{10} \frac{\mathrm{E}_{0}}{\mathrm{E}_{\mathrm{sc}}}+\frac{4}{5}\right)^{2}-\frac{4}{5}}\right] \\
& \varepsilon_{0}=750\left(\mathrm{f}_{\mathrm{c}}^{\prime}\right)^{0.35} \times 10^{-6} \\
& \mathrm{E}_{0}=15050\left(\mathrm{f}_{\mathrm{c}}^{\prime} / 10\right)^{1 / 3} \\
& \mathrm{E}_{\mathrm{sc}}=\mathrm{f}_{\mathrm{c}}^{\prime} / \varepsilon_{0}
\end{aligned}
$$

Burada $f_{c}^{\prime}$ betonun tek eksenli basınç dayanımını, $\varepsilon_{0} f_{c}^{\prime}$ değerine karşıllk gelen birim şekil değiştirmeyi, $E_{0}$ başlangıç elastiste modülünü, $E_{s c} f_{c}^{\prime}$ değerine karşılık gelen sekant modülünü ifade etmektedir.

Çekme altındaki davranışı UYPLB için normal dayanımlı betonun davranışından farklıdır. Normal betonda kırılma sonrası yük azalma hızı çok yüksek ve deformasyon çok düşük olmasına karşın, lifli betonda çatlama sonrası yükün daha da arttığı görülür. UYPL betonda lifler köprü görevi görerek betonda oluşan mikro çatlakların büyümesini engelleyip beton matrisi üzerinden boşalan gerilmeyi karşılar ve lokal çatlak oluşana kadar bir miktar daha gerilme almasını sağlar. Gerilme transferi sebebiyle, çatlağın yayılması için gerekli olan enerji miktarı da normal betona göre çok daha fazla olmaktadır (Redaelli ve Muttoni , 2007). İdealleştirilmiş model yaklaşımı çekme davranışını elastik bölge, dayanım pekleşmesi ve dayanım azalması olmak üzere 3 kısma ayırmaktadır (Şekil 6) (Wille ve diğ., 2011).

Çekme davranışının tanımlanmasında elastik kısımda çekme gerilmesi-birim şekil değiştirme ilişkisi çatlama dayanımının $\left(\sigma_{c c}\right) \% 90-95$ 'ine kadar lineer olarak ilerler. Dayanım pekleşmesi bölgesinde çekme dayanımına $\left(\sigma_{p c}\right)$ ulaşana kadar mikro çatlaklar ve inelastik şekil değişimleri meydana gelir. Dayanım yumuşaması kısmında ise lokal çatlaklar oluşur ve dayanım azalmaya başlar.

$\mathrm{Bu}$ çalışmada referans alınan deneysel çalışmada, betonun çekme davranışını elde etmek için laboratuvar ortamında eğilme testi uygulanmış, daha sonra geri analiz metodu ile çekme gerilmesi-çatlak genişliği grafiği elde edilmiştir. Deneysel çalışmadan edilen çekme gerilmesi- çatlak genişliği eğrisi Fransa İnşaat Mühendisliği Topluluğu (AFGC) tarafından önerilen ampirik bağıntılar kullanılarak gerilme-birim şekil değiştirme eğrisine dönüştürülebilmektedir. (Şekil 7b). 


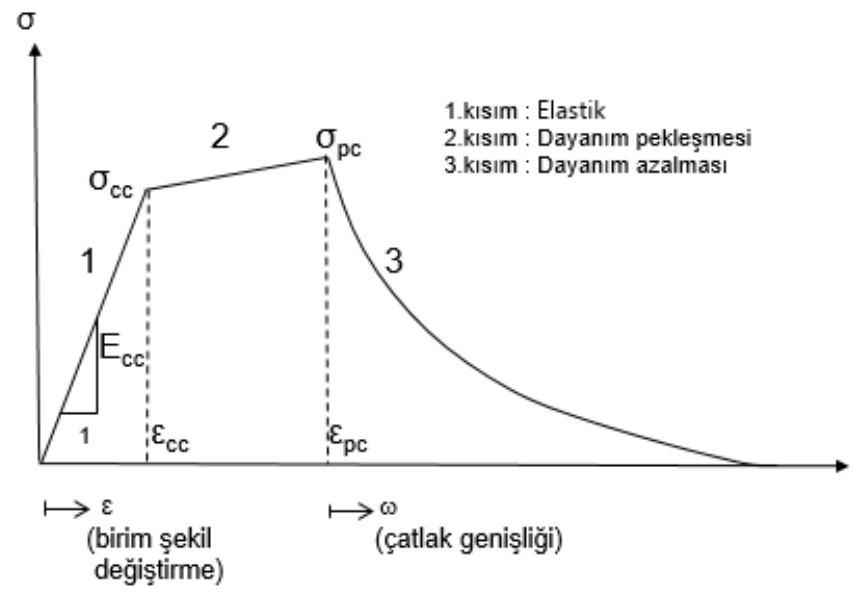

Şekil 6. UYPLB için idealleştirilmiş çekme davranışı (Wille ve diğ., 2011) Figure 6. Idealized tension behavior for UHPFRC (Wille et al., 2011)

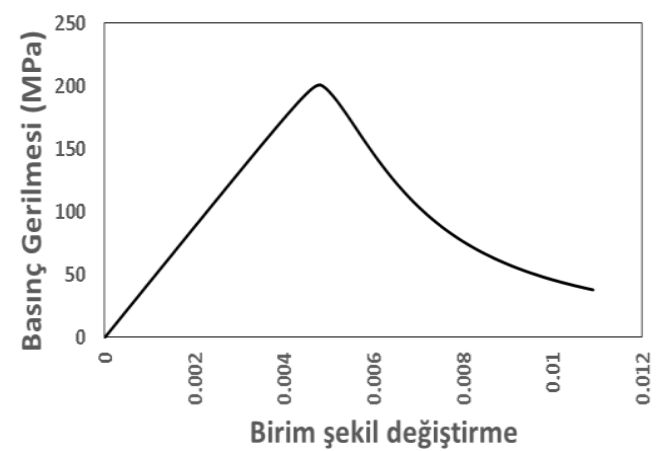

a)

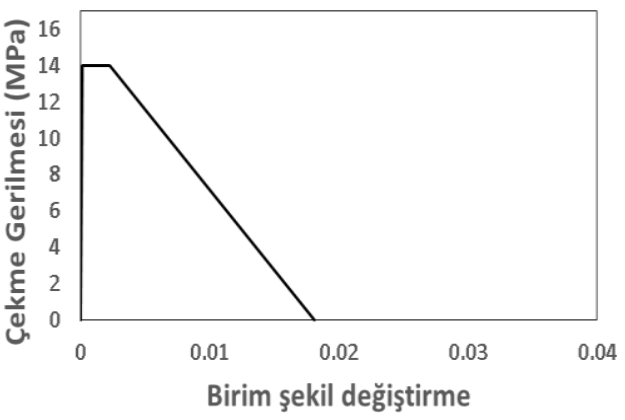

b)

Şekil 7. Beton basınç (a) ve çekme (b) davranışı (UH-1.06\%)

Figure 7. Concrete compressive (a) and tensile (b) behavior (UH-1.06\%)

$\varepsilon_{0.3}=\frac{w_{0.3}}{l_{c}}+\frac{f_{t j}}{\gamma_{b f} E_{c}}$

$\varepsilon_{1 \%}=\frac{w_{1 \%}}{l_{c}}+\frac{f_{t j}}{\gamma_{b f} E_{c}}$

$\varepsilon_{\text {lim }}=\frac{l_{f}}{4 l_{c}}$

$\mathrm{Bu}$ bağıntılarda $\varepsilon_{0.3}$, çatlak genişliğinin $0.3 \mathrm{~mm}$ olduğu birim şekil değiştirmeyi $\left(w_{0.3}\right), \varepsilon_{1 \%}$, kiriş yüksekliğinin \%1'i kadar çatlak genişliğinin $\left(w_{1 \%}\right)$ olduğu birim şekil değiştirmeyi ifade etmektedir. lf lif uzunluğunu, $\gamma_{b f}$ kismi güvenlik faktörünü, $E_{c}$ beton elastisite modülünü göstermektedir. $1_{c}$ ise karakteristik uzunluktur ve kiriş yüksekliğinin 2/3'ü olarak ifade edilmektedir. Deneysel verilerden elde edilen parametreler kullanılarak elde edilen beton ve donatı mekanik davranışı, Şekil 7 ve Şekil 4'de, Beton Hasar Plastisite modelini oluşturmak için gerekli parametreler Çizelge 2'de verilmektedir. Çekme davranışının modellenmesinde K katsayısı 1.25 olarak alınmıştır. Nümerik modelin analiz sonuçlarına çözüm ağı sıklığının etkisini belirlemek üzere 50, 25 ve 12.5mm kenar uzunluğuna sahip sonlu elemanlarla oluşturulmuş numuneler üzerinde analizler yapılmış analiz süresi ve sonuçların yakınsaması açısından optimum değer olarak $25 \mathrm{~mm}$ mesh yoğunluğu belirlenmiştir.

Geliştirilen sonlu eleman modelinin UYPLB ile üretilen betonarme kirişin davranışını gerçekçi bir şekilde simüle edebilmesi için modele etki eden BHP modeli temel parametrelerinin kesin bir şekilde belirlenmesi gerekmektedir (Çizelge 2). Literatürde yapılan sayısal çalışmalarda $\in, \sigma_{b o} / \sigma_{c o}, K_{c}$ değerlerinin modelin davranışını belirgin bir şekilde etkilemediği ortaya konulmuştur. Bu çalışmada bu 
değerler seçilirken ABAQUS Kullanıcı Dökümanında (User Manuel) önerilen değerler dikkate alınmıştır. Eksenel basınç altında betonda kritik gerilmeye kadar hacimsel değişimler poisson oranıla belirlenirken kritik gerilme sonrası oluşan plastik hacimsel değişimler dilasyon açısı parametresiyle dikkate alınmaktadır (Sümer, 2010). Sonlu eleman analizlerinde 3 farklı dilasyon açısı değeri ile analiz yapılmış ve $10^{\circ}$ dilasyon açısının deney verisindeki tepe noktası değerine daha yakın sonuç verdiği tespit edilmiştir. Bununla birlikte belirlenen dilasyon açısının Othman ve Marzouk (2017) ve Chen ve Graybeal (2012) tarafından önerilen değerlerle de uyumlu olduğu belirlenmiştir.

Çizelge 2. BHP modeli temel parametreleri Table 2. CDP model basis parameters

\begin{tabular}{cc} 
Table 2. CDP model basis parameters & \\
\hline Parametre & Değer \\
\hline Dilasyon açısı $(\psi)$ & 10 \\
\hline$\sigma_{b o} / \sigma_{c o}$ & 1.05 \\
\hline Eksantriste parametresi $(\epsilon)$ & 0.1 \\
\hline$K_{c}$ & $2 / 3$ \\
\hline Viskozite parametresi $(\eta)$ & 0.0001 \\
\hline
\end{tabular}

\section{SONLU ELEMAN MODELININN DOĞRULANMASI (FINITE ELEMENT MODEL VALIDATION)}

Deneysel çalışmalarda çarpma ağırlığının $1.60 \mathrm{~m}$ yükseklikten serbest bırakılmasıyla elde edilen sonuçlar ile nümerik model sonuçlarının karşılaştırması Şekil 8'de sunulmuştur. Ayrıca deney ve sayısal modelden elde edilen sonuçlar ve hata oranları Çizelge 3'de özetlenmiştir.

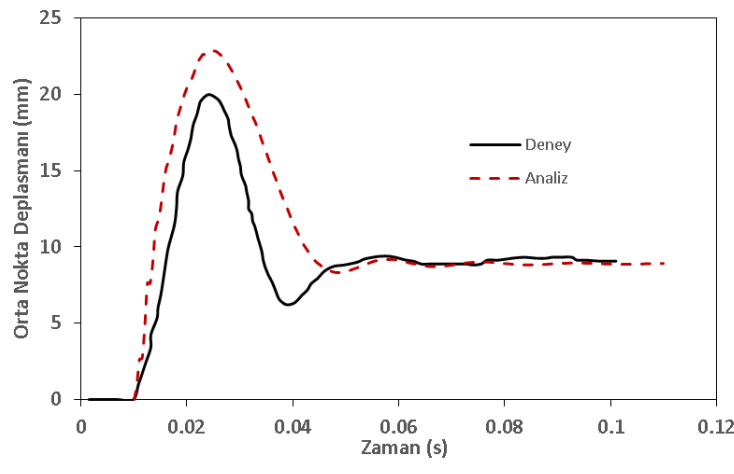

a) UH-N

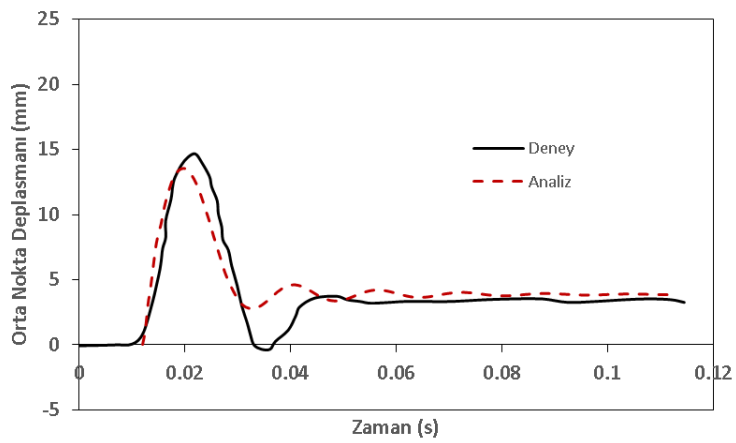

c) $\mathrm{UH}-1.06 \%(\rho=1.06 \%)$

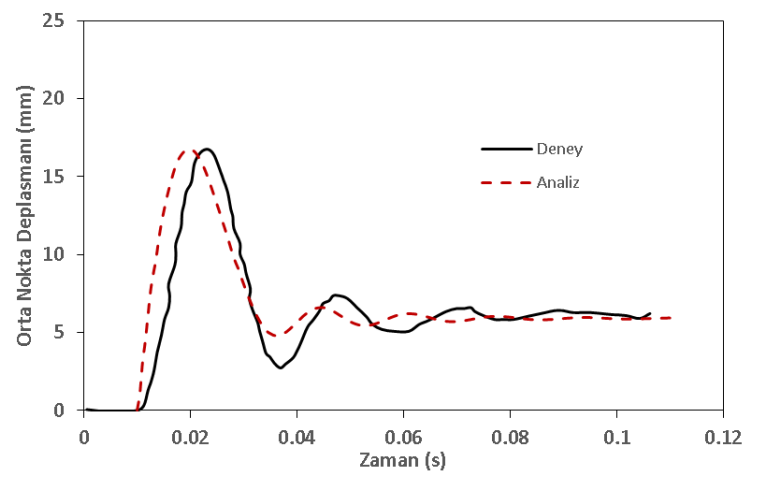

b) UH-0.53\% $(\rho=0.53 \%)$

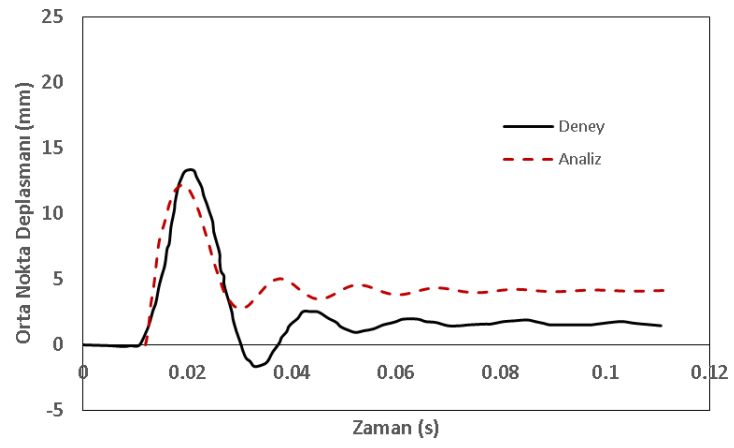

d) UH-1.71\% $(\rho=1.71 \%)$

Şekil 8. Deney ve analiz sonuçlarından elde edilen Deplasman-Zaman grafiği

Figure 8. Displacement-Time graph obtained from experiment and analysis results 
Şekil 8' deki grafikler ve elde edilen sonuçlar dikkatle incelendiğinde sonlu eleman modeli ile deneysel sonuçların oldukça uyumlu olduğu belirlenmiştir. UYPLB ile üretilen betonarme kirişlerin orta noktasında oluşan deformasyonların maksimum değerlerinde hata oranının \%8 civarlarında olduğu, donatısız kiriş numunesinde ise bu değerin \%14 seviyelerine çıtığı gözlemlenmektedir. Kalıcı deformasyonlar açısında ise hata oranının \%5'in altında kaldığı ve sadece donatı oranının en yüksek olduğu UH-1.71\% kiriş numunesinde hata oranının \%186 seviyesine çıktığı görülmektedir. Analizlerin tamamında aynı geliştirilmiş sonlu eleman modelinin kullanıldığı ve BHP modeli temel parametrelerinin sabit tutulduğu dikkate alındığında sonlu eleman modelinin UYPLB ile üretilen betonarme kirişlerin çarpma yükleri etkisi altındaki davranışını başarıyla simüle ettiği görülmektedir. Dolayısıyla geliştirilen sonlu eleman modeli, çarpma etkisindeki UYPLB ile üretilen betonarme kirişlerin davranışının incelenmesinde güvenle kullanılabilir.

Çizelge 3. Deney sonuçları ile sonlu eleman modeli sonuçlarının karşılaştırılması

\begin{tabular}{c|ccc|ccc}
\multicolumn{7}{c}{ Table 3. Comparison of experiment results and finite element model results } \\
\hline \multirow{2}{*}{ Numune } & \multicolumn{3}{|c|}{ Maksimum deformasyon } & \multicolumn{3}{c}{ Kalıc deformasyon } \\
\cline { 2 - 8 } & $\begin{array}{c}\text { Deney } \\
(\mathrm{mm})\end{array}$ & $\begin{array}{c}\text { Analiz } \\
(\mathrm{mm})\end{array}$ & Hata & $\begin{array}{c}\text { Deney } \\
(\mathrm{mm})\end{array}$ & $\begin{array}{c}\text { Analiz } \\
(\mathrm{mm})\end{array}$ & Hata \\
\hline $\mathrm{UH}-\mathrm{N} \quad(\rho=0.00 \%)$ & 19.98 & 22.82 & 0.14 & 9.07 & 8.90 & 0.02 \\
\hline $\mathrm{UH}-0.53 \%(\rho=0.53 \%)$ & 16.75 & 16.75 & 0.00 & 6.21 & 5.91 & 0.05 \\
\hline $\mathrm{UH}-1.06 \%(\rho=1.06 \%)$ & 14.67 & 13.55 & 0.08 & 3.27 & 3.83 & 0.17 \\
\hline $\mathrm{UH}-1.71 \%(\rho=1.71 \%)$ & 13.32 & 12.22 & 0.08 & 1.45 & 4.15 & 1.86 \\
\hline
\end{tabular}

\section{PARAMETRÍK ÇALIŞMA (PARAMETRIC STUDY)}

Doğrulanan sonlu eleman modeli kullanılarak parametrik bir çalışma yapılmış ve UYPLB ile üretilen betonarme kirişlerin çarpma etkisi altındaki davranışı sayısal olarak incelenmiştir. Yapılan parametrik çalışmada UYPLB ile üretilen betonarme kirişlerin çarpma davranışına donatı oranının ve çarpma hızının (düşme yüksekliği) etkisi araştırılmıştır (Çizelge 4).

Çizelge 4. Parametrik Çalışma Detayları Table 4. Parametric Study Details

\begin{tabular}{|c|c|c|c|}
\hline & $\mathrm{h}(\mathrm{m})$ & $\mathrm{V}(\mathrm{m} / \mathrm{s})$ & \\
\hline \multirow{4}{*}{$\begin{array}{c}\text { UH-N } \\
(\rho=0.00 \%)\end{array}$} & 0.50 & 3.13 & Nümerik \\
\hline & 1.00 & 4.43 & Nümerik \\
\hline & 1.60 & 5.60 & Deney \\
\hline & 3.00 & 7.67 & Nümerik \\
\hline \multirow{4}{*}{$\begin{array}{l}\text { UH- } 0.53 \% \\
(\rho=0.53 \%)\end{array}$} & 0.50 & 3.13 & Nümerik \\
\hline & 1.00 & 4.43 & Nümerik \\
\hline & 1.60 & 5.60 & Deney \\
\hline & 3.00 & 7.67 & Nümerik \\
\hline \multirow{4}{*}{$\begin{array}{l}\text { UH-1.06\% } \\
(\rho=1.06 \%)\end{array}$} & 0.50 & 3.13 & Nümerik \\
\hline & 1.00 & 4.43 & Nümerik \\
\hline & 1.60 & 5.60 & Deney \\
\hline & 3.00 & 7.67 & Nümerik \\
\hline \multirow{4}{*}{$\begin{array}{l}\text { UH-1.71\% } \\
(\rho=1.71 \%)\end{array}$} & 0.50 & 3.13 & Nümerik \\
\hline & 1.00 & 4.43 & Nümerik \\
\hline & 1.60 & 5.60 & Deney \\
\hline & 3.00 & 7.67 & Nümerik \\
\hline
\end{tabular}




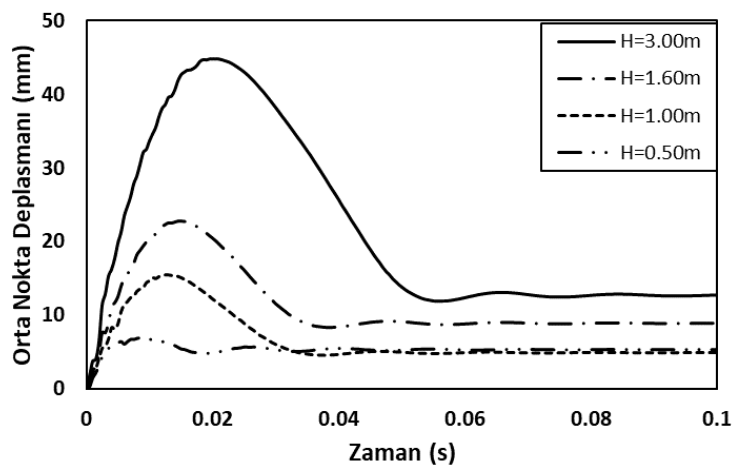

a) $\operatorname{UH}-\mathrm{N}(\rho=0.00 \%)$

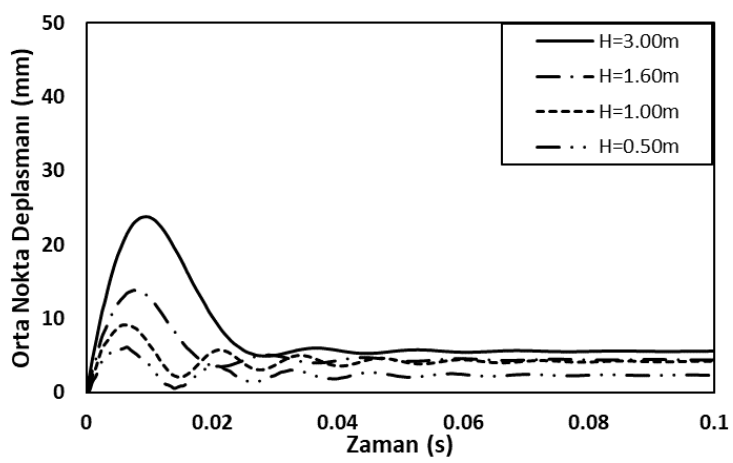

c) $\mathrm{UH}-1.06 \%(\rho=1.06 \%)$

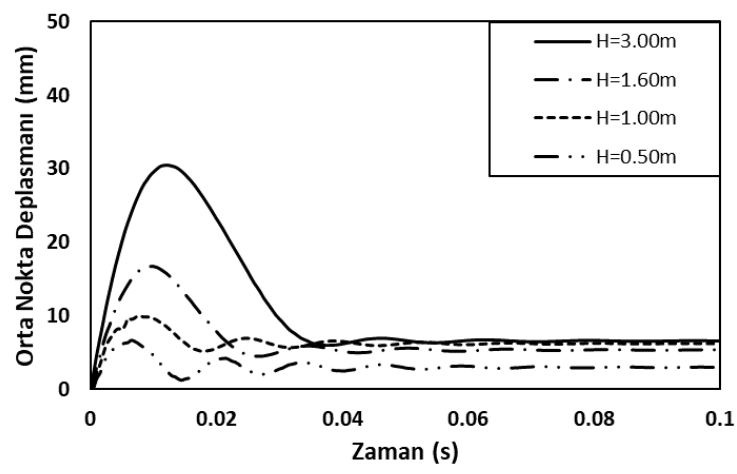

b) $\mathrm{UH}-0.53 \%(\rho=0.53 \%)$

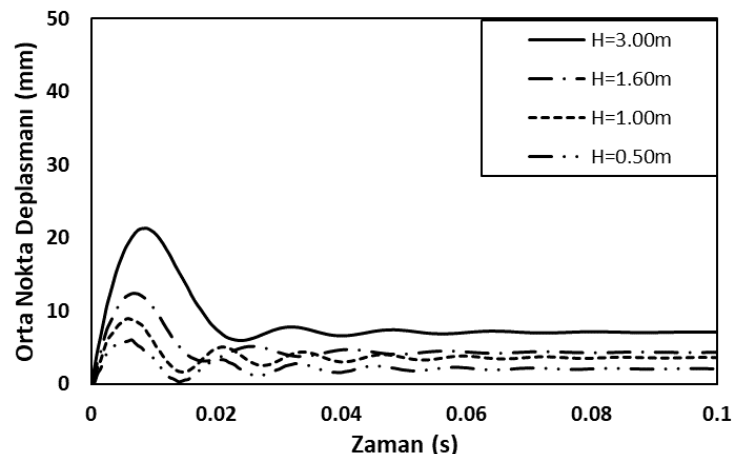

d) $U H-1.71 \%(\rho=1.71 \%)$

Şekil 9. Çarpma etkisindeki UYPL betonarme kirişlerde deplasman-zaman değişimi

Figure 9. Displacement-time in UHPFRC beams under impact

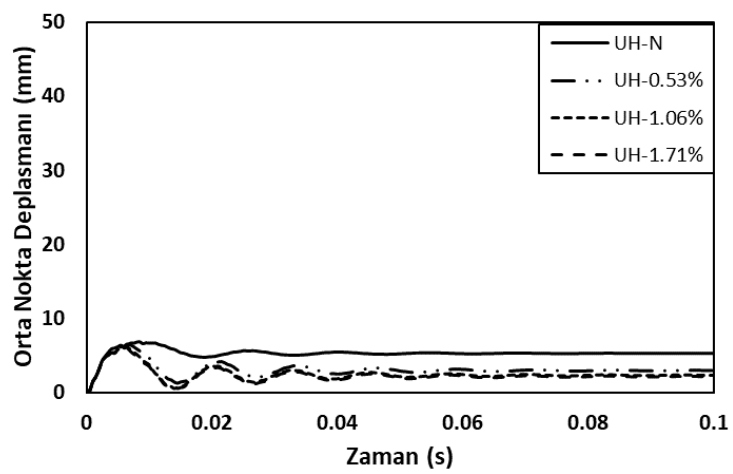

a) $\mathrm{H}=0.50 \mathrm{~m}$

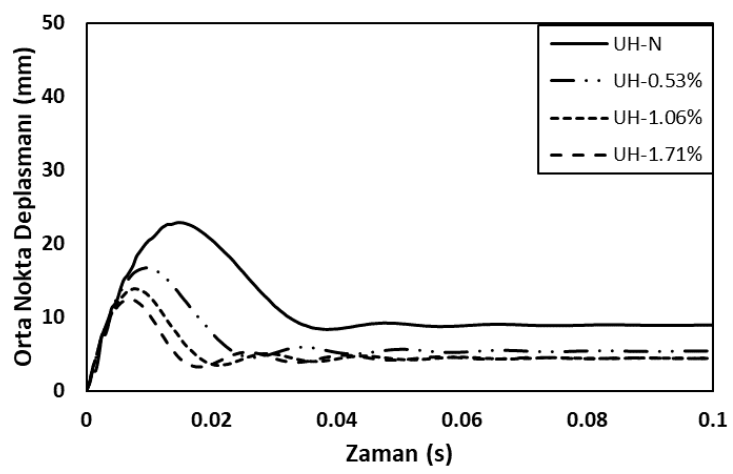

c) $\mathrm{H}=1.60 \mathrm{~m}$

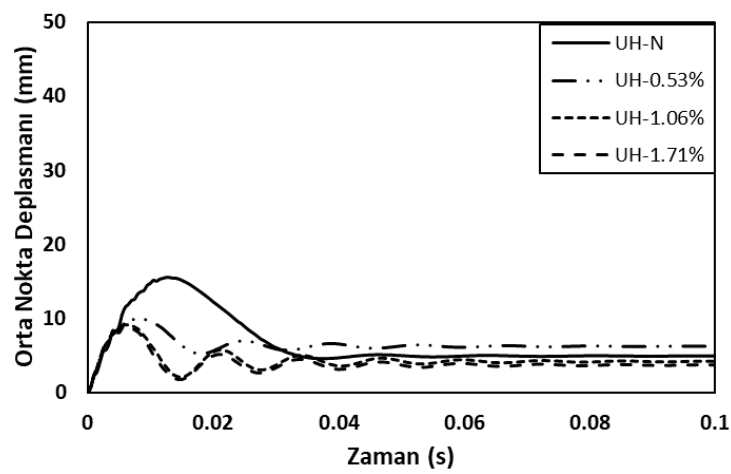

b) $\mathrm{H}=1.00 \mathrm{~m}$

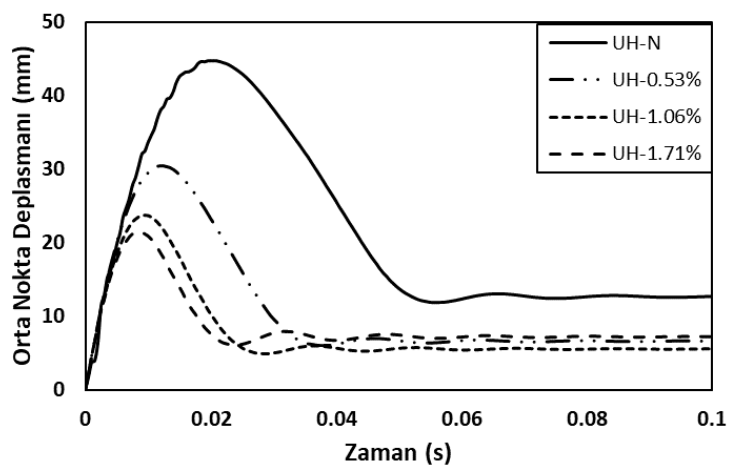

d) $\mathrm{H}=3.00 \mathrm{~m}$

Şekil 10. Farklı donatı oranındaki UYPL betonarme kirişlerde çarpma hızının etkisi Figure 10. Effect of impact drop velocity on UHPFRC beams with different reinforcement ratios 
Parametrik çalışmada sırasıyla $0.00,0.53,1.06$ ve 1.71 donatı oranlarına sahip sonlu eleman modellerinin dört farklı çarpma hızı (düşme yüksekliği) için doğrusal olmayan analizleri gerçekleştirilmiştir. Kirişlerin çarpma davranışı kiriş orta noktasının deformasyonunun zamanla değişimi ve kalıcı deformasyonun belirlenmesi üzerinden değerlendirilmiştir.

Şekil 9'dan da görüldüğü gibi, aynı donatı oranına sahip betonarme kirişlerde çarpma hızı (düşme yüksekliği) değişiminin; maksimum yerdeğiştirme ve kalıcı yerdeğiştirme üzerinde belirgin bir etkiye sahiptir. Çarpma hızının artması ile maksimum yerdeğiştirme ve kalıcı yerdeğiştirme değerlerinde artış gözlemlenmekle birlikte donatı oranı artması durumunda ise bu değerlerde azalmalar oluşmaktadır.

Şekil 10 dikkatle incelendiğinde, aynı çarpma hız değerinde, donatı oranı arttıkça maksimum deplasman değerlerinin azaldığı ve numunenin maksimum deplasman değerine ulaşana kadar geçen sürenin de kısaldığı görülmüştür. Kalıcı yerdeğiştirme değerlerinin donatı oranı artarken azaldığı buna karşılık ise çarpma hızı artarken arttığı gözlemlenmiştir.

\section{SONUÇ ve TARTIŞMALAR (RESULTS and DISCUSSIONS)}

Bu çalışmada, çarpma yükü altında ultra yüksek performanslı lifli betonarme kirişlerin nümerik olarak analizine imkân sağlayan bir sonlu eleman modeli oluşturulmuştur. Geliştirilen sonlu eleman modelinin doğrusal olmayan analizlerinden elde edilen sonuçlar, deney sonuçları ile oldukça iyi bir uyum içerisindedir. UYPLB için seçilen malzeme modeli ve bu malzeme modeli değerleri ile tanımlanan BHP modelinin bu kirişlerin nümerik analizleri için elverişli olduğu, önerilen beton basınç ve çekme eğrilerinin dinamik analizlerde yüksek dayanımlı ve lif katkılı betonların davranışını modellemede kullanılabilir olduğu analiz sonuçlarıyla açıkça ortaya konulmuştur. Ayrıca önerilen model mevcut kirişlerin yenilme mekanizmalarını da doğru bir şekilde tahmin etmektedir. Dolayısıyla UYPLB ile üretilen betonarme kirişlerin çarpma yükleri altındaki davranışı ABAQUS yazılımı kullanılarak gerçekçi bir şekilde simüle edilebileceği görülmektedir.

Parametrik çalışma sonuçları incelendiğinde boyuna donatı oranının azalması ile maksimum ve kalıcı yerdeğiştirmelerde belirgin artışlar olduğu gözlemlenmiştir. Betonarme kirişlerin deforme olmasında en etkili parametrenin çarpma hızının değişimi olduğu belirlenmiştir. Çarpma hızları açısından değerlendirildiğinde ise, hız artması ile kiriş ortasındaki maksimum ve kalıcı yerdeğiştirmelerde artışlar oluşmaktadır.

\section{KAYNAKLAR (REFERENCES)}

ABAQUS Documentation, 2018, Dassault Systèmes, 10 rue Marcel Dassault CS 4050178946 VélizyVillacoublay Cedex, SE, France.

AFGC (Association Francaise du Genil Civil) 2013, Ultra High Performance Fibre-Reinforced Concretes Recommendations, Fransa.

Birtel, V., Mark, P., 2006, "Parameterised finite element modelling of RC beam shear failure", In ABAQUS users' conference, ss. 95-108.

Chen, L., Graybeal, B. A., 2012, “Modeling Structural Performance of Ultra High Performance Concrete IGirders", Journal of Bridge Engineering, Cilt 17, Sayı 5, ss. 754-764.

Curbach, M., Speck, K., 2008, “Ultra high performance concrete under biaxial compression”, In Ultra High Performance Concrete (UHPC): Proceedings of the Second International Symposium on Ultra High Performance Concrete, Kassel, Germany, Sayı 10, ss. 477-484.

Demirtaş, G., Çağlar, N., Sümer, Y. (2018). Çarpma Etkisindeki UltraYüksek Performanslı Lifli Betonarme Kirişlerin Sonlu Elemanlar Analizi. Academic Perspective Procedia, 1 (1), 1126-1135. DOI: 10.33793/acperpro.01.01.180

Demirtaş, G, 2019, Çarpma Etkisindeki Ultra Yüksek Performansli Lifli Betonarme Kirişlerin Sonlu Elemanlar Analizi, Yüksek Lisans Tezi, Sakarya Üniversitesi, Türkiye. 
Earij, A., Alfano, G., Cashell, K., Zhou, X., 2017, “Nonlinear three-dimensional finite-element modelling of reinforced-concrete beams: Computational challenges and experimental validation", Engineering Failure Analysis, Sayı:82, ss. 92-115.

Fujikake, K., Senga, T., Ueda, N., Ohno, T., Katagiri, M., 2006, "Study on impact response of reactive powder concrete beam and its analytical model", Journal of advanced concrete technology, Say1 4(1), ss. 99-108.

Lu, Z. H., Zhao, Y. G., 2010, “Empirical Stress Strain Model for Unconfined High Strength Concrete under Uniaxial Compression", Journal of Materials in Civil Engineering, Sayı 22(11), ss. 1181-1186.

Lubliner, J., Oliver, J., Oller, S., Oñate, E., 1989, "A plastic-damage model for concrete", International Journal of solids and structures, Say1 25(3), ss. 299-326.

Othman, H., Marzouk, H., 2016, "Impact response of ultra-high-performance reinforced concrete plates", ACI Structural Journal, Sayı 113(6), ss. 1325-1334.

Othman, H., Marzouk, H., 2017, “Finite Element Analysis of UHPFRC Plates under Impact Loads", AFGCACI-fib-RILEM Int. Symposium on Ultra-High Performance Fibre-Reinforced Concrete, UHPFRC, ss. 337-346.

Redaelli, D., Muttoni, A., 2007, “Tensile Behaviour of Reinforced Ultra-High Performance Fiber Reinforced Concrete Elements", In fib Symposium, Dubrovnik, ss. 267-274.

Singh, M., Sheikh, A. H., Ali, M. M., Visintin, P., Griffith, M. C., 2017, “Experimental and Numerical Study of The Flexural Behaviour of Ultra-High Performance Fibre Reinforced Concrete Beams", Construction and Building Materials, Sayı 138, ss. 12-25.

Sümer, Y., 2010, “FRP Elemanlarla Güçlendirilmiş Hasarlı Betonarme Kirişlerin Doğrusal Olmayan Sonlu Elemanlar Yöntemiyle Analizi", Doktora Tezi, Sakarya Üniversitesi, Turkiye

Wille, K., Kim, D. J., Naaman, A. E., 2011, “Strain-hardening UHP-FRC with low fiber contents. Materials and Structures", Say1 44(3), ss. 583-598.

Yoo, D. Y., Banthia, N., 2017, "Mechanical and structural behaviors of ultra-high-performance fiberreinforced concrete subjected to impact and blast", Construction and building materials, Say1 149, ss. 416-431.

Yoo, D. Y., Banthia, N., Kim, S. W., Yoon, Y. S., 2015, “Response of ultra-high-performance fiber-reinforced concrete beams with continuous steel reinforcement subjected to low-velocity impact loading", Composite Structures, Sayı 126, ss. 233-245.

Yoo, D. Y., Banthia, N., Yoon, Y. S., 2017, “Impact Resistance of Reinforced Ultra-High-Performance Concrete Beams with Different Steel Fibers", ACI Structural Journal, Sayı 114(1) ss.113-124. 